\title{
A Preliminary Discussion of Digital Transformation and Semantic Interoperability to Support the Information Exchange in the Business Process
}

\author{
Lucas Yoshio NAKANO ${ }^{\mathrm{a}}$, Pedro Henrique BERTOLDI ${ }^{\mathrm{b}}$, Anderson Luis SZEJKA ${ }^{\mathrm{a}, 1}$ \\ and Osiris CANCIGLIERI JUNIOR ${ }^{\mathrm{a}}$ \\ andustrial and Systems Engineering Graduate Program, Pontifical Catholic \\ University of Parana, Curitiba, Brazil \\ ${ }^{\mathrm{b}}$ Automation and Control Engineering Program, Pontifical Catholic University of \\ Parana, Curitiba, Brazil
}

\begin{abstract}
The development of interoperability is more and more an essential task for all kinds of organizations. It needs to be measured, verified, and continuously improved. With the advent of the Internet of Things, Industry 4.0, Digital Transformation, as well as all technologies it brings, such as big data, cloud computing, and mobile applications, this subject become quite ordinary and necessary, not only in a manufacturing scenario but also in a business process. As crucial benefits, it can bring possible gains for developers and users, also reduce the efforts to communicate multiple and different platforms. Like all new implementations, there are significant challenges that have to be overcome to allow satisfactory results. In this paper, after a systematic literature review to better understand the technologies and this new situation, we conduct a study involving a case in a business process, presenting some actions that can be executed and technologies that can be implemented to reach a well interoperable environment. For instance, to analyze the interoperability maturity level and to adopt ontologies as an alternative to integrate heterogeneous systems. Finally, in the last part of the paper, we give conclusions and perspectives for futures works.
\end{abstract}

Keywords. Enterprise interoperability, digital transformation, digitalization, ontologies, transdisciplinary.

\section{Introduction}

In the globalization scenario, enterprises are challenging several tests, like the emergence of new technologies, personalized customer demand, globalization. To handle that, most companies are gradually changing their vision and the market structure, becoming more collaborative with whom it gets involved. It permits all stakeholders to create more value for their business.

As observed in source [1], it is crucial since the current customers are more connected to the internet, especially the digital natives, for whom technology is part of daily life. It has caused a transformation in the way to select, buy, and consume products

\footnotetext{
${ }^{1}$ Corresponding Author -anderson.szejka@pucpr.br.
} 
and services. This kind of change has been called Digital Transformation (DX), otherwise called Digitalization. Nowadays, the manufacturing DX is the most common, but others exist, like the Digital Business Transformation, which is also becoming essential for the entire market. Data analytics, cloud computing, augmented reality, pattern recognition, artificial intelligence, and machine learning are some technologies that enable those changes.

All those processes have to break down barriers that, somehow, are slowing or making it impossible. To source [1], organizations need to deal with those companies are in-depth traditional sectors while finding an alternative to adapt themselves as soon as possible, since customers are imposing their rules faster and faster. The inadequate or overly heterogeneous systems, companies' structure or culture, lack of DX strategies, ROI (Return on Investment) visibility, and shortage of skills and a qualified labour force are some points of [2].

As a successful result, companies can connect people, businesses, and things. Highly influenced by disruptive IT, it enables them to create new products and services or make them more efficient, with a competitive advantage, generating good results not only for the economy, but also for society, industry, and business [3]. For instance, Vivo has adopted the agile-squad model and open innovation as the basis of its DX implementation; Hospital Samaritano and Hospital Sírio-Libanês had invested in it to improve their patient experience and operational performance [1].

To source [4], the business DX is a set of 7 elements: business model, organizational structure, digital skills of employees, digitization of business processes, IT infrastructure, digitization of products/services, and digital channels for interaction with clients.

The digital transformation is different for each company since there are infinity strategy possibilities. Knowing that and that exist several ways to implement the DX, the communication between companies, even inside themselves, can become a huge barrier. In this context, interoperability is a must to make everything work correctly, making systems share and use the information without losing it or having a weak interpretation [5].

\section{Problem Statement}

Digital transformation has been placed users at the heart of the corporate strategy. Indeed, they are more and more demanding concerning products and services' quality and custom. Nevertheless, it does not concern only the company's customers but also collaborators and employees. Mobility, connected objects, and collaborative platforms are investments done by enterprises to provide value-added services to them [1].

Since that, DX is providing business and market dynamism, principally in technologyintensive industries. Products, business models, company culture, labour market are continuously changing, and all companies need to adapt themselves as soon as possible to prevent being consumed by the new reality. Some of them are reorganizing themselves to work with two modes. In the first one, companies keep a traditional business operating. In the second one, the disruptive, they seek opportunities to introduce products and services that take advantage of the new market. However, most companies do not commercialize technologies that may cannibalize their own business unless a big part of the market needs it. With that, disruptive companies explore the gap left by the market leaders, developing new products and services that fill customers' additional requirements [1][2]. 
One of the most crucial steps of DX is the transformation strategy. A successful scenario must have a good plan and a well-defined reengineering and optimization of the business process. Without that, companies may become more focused only on technology instead of on the customer.

Even though all benefits digital transformation can bring, there are also adverse outcomes and potential issues, principally in the security and privacy domain. Eliminate them is necessary, or they may cause serious problems. Decision-making algorithms, for instance, carry significant risks since big decisions can be made without human concern. Since that, this kind of technology should be carefully developed and tested [6].

DX is opening the path for technology innovation, new business models, and crossindustry collaboration. The increased number of software, intelligent machines, systems, and applications created complications involving interoperability. It exists more than only among the same level or enterprise. Interoperability can share data and information between interacting enterprises and their related systems. An interoperability problem can cause several difficulties and can drastically influence the performance and the outcomes of enterprise business [5]. Accordingly [7], the United States Department of Commerce Technology Administration estimated that inadequate interoperability between systems in the United States Capital Facilities Industry was U\$15.8 billion for them.

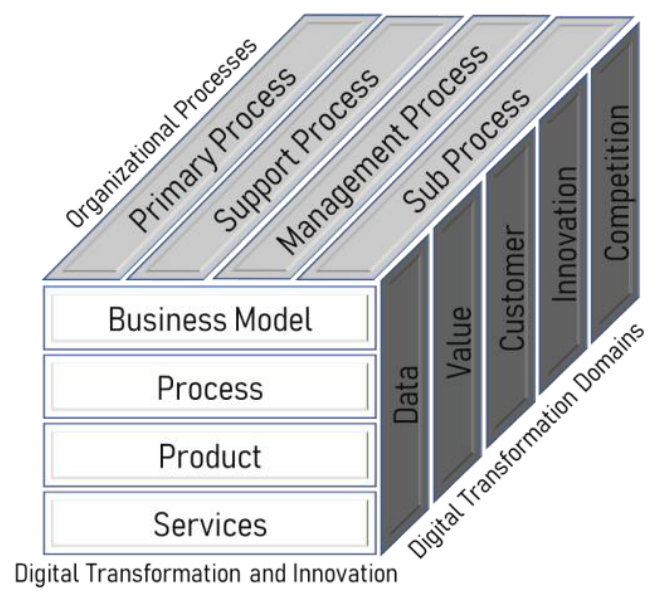

Figure 1. Business Digital Transformation Dimensions.

For analysing the barriers of DX implementation, it is possible to consider three dimensions, as illustrated in Figure 1: the dimension of the domain, the organizational process dimension, and the digital transformation and innovation type dimension. The first dimensions concern the set of domains involved in the company business or sector where DX will be applied. Here, each domain has its digital transformation and innovation type since its needs are different from the others require different approaches. The second dimension is related to all activities necessary to transform all its resources into products and services. The last represents all layers that the DX can achieve, from the product to the entire business process.

The interoperation between all dimensions is also identified. It is crucial to maintain the system working correctly, besides allowing quick and easy implementation of future technologies and systems. Moreover, it permits a transparent sharing of information and the continuous improvement of the entire environment. 


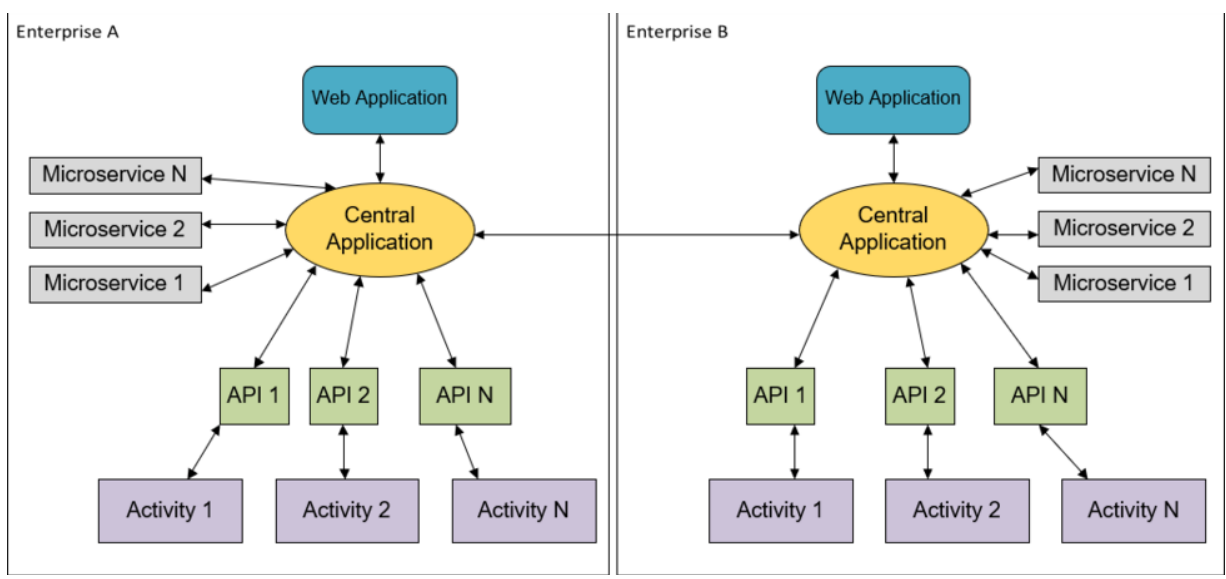

Figure 2. Communication between enterprises and inside them.

Figure 2 shows a model capable of solving the problem of integrating information and digitizing its processes. It is represented the integration of two companies but can be applied to the integration of $\mathrm{N}$ companies.

To carry out the necessary activities, the model makes use of several APIs and Microservices. Those techniques are widely used in the development of MRP and ERP systems, and their modularization capacity makes the development of new tools more efficient and robust [8].

In the "Web Application" block exists a web application, where all the services that the various employees of the company can use.

Right below, there is the "Central Application" block. This layer is responsible for managing the requests from inside and outside the company. It allows filtering information and requests for the APIs that do the work. This layer is the most important for this model, as it is in this layer where the integration of several companies occurs. This role is just to route calls to the distinct APIs, and it is crucial that, in this layer, no functionality of the process to be digitized is implemented.

The "Central Application" has the role of integrating several Microservices and APIs, which are responsible for carrying out all the activities necessary for process digitization in question. It is recommendable that, during development, standards such as semantic WEB and ISA 95 be used, especially in this layer.

\section{Technological Background}

This section analyses existing works that support the understanding of what Digital Transformation is and what is vital during implementation. Besides, it is treated about interoperability (which is viewed as a reliable way to communicate with all other systems around it).

\subsection{Digital Transformation}

As related in source [9], digital transformation is understood as to how technologies influence aspects of human life. It is possible to unify this idea with the role of digital 
transformation in influence how software is developed to facilitate integration and support activities [8].

Nowadays, it is common to use multiple platforms, such as tablets and cell phones, to do plenty of activities. As a result, companies started to use new development methods for their applications instead of developing the same applications for each existing platform on the market [8].

The digital transformation brings significant changes, such as integration of various sectors of the company and distinct companies, new market opportunities, and gains in competitiveness [2]. More than this, the digital transformation of society brings what is called Hyper-Connected World, where human and artificial actors are linked with each other, allowing a new way to execute business processes [3].

With customer satisfaction and operational excellence as motivation, digital transformation proves to be a decent solution to optimize existing processes or assist in the optimized processes creation since it has an attractive implementation cost. It occurs since most digitization problems can be solved with software development to integrate existing systems and tools [2]. However, most companies do not have a good plan for implementation or an idea of how to start their DX journey. In this scenario, a welldefined strategy is crucial [10].

In the development of digital transformation software, it is recommended to use development techniques based on Microservices and APIs (Application Programming Interface). Microservices can reduce development time as they can be developed independently for each activity they must perform and can communicate with varied technologies. On the other hand, APIs can establish standards for how distinguished applications communicate [8].

APIs can also be used to provide functionality and information for various platforms, providing robustness and flexibility. Some examples of APIs on the market are the Google and Facebook APIs [11].

\subsection{Interoperability}

In the globalization scenario, enterprises are challenging several barriers, like the emergence of new technologies, personalized customer demand, globalization itself, for example. To handle that, most companies are gradually changing their vision and becoming more collaborative with whom it gets involved. It permits all stakeholders to create more value for their business. In this context, interoperability is a must to make everything work correctly. Systems can share and use the information without losing it or having a weak interpretation [5].

Interoperability is also necessary between systems in the same enterprise. Each year, the need for more information and data is becoming more significant. In most cases, it is crucial to share data among departments, factories, countries so on. Communication should be complicated since there are heterogeneous domains, different languages, and environments where the same symbol may have distinct meanings or overlap it [12]. But to it be clear, some technologies should be applied, such as OWL (Web Ontology Language), to allow everyone to understand the information in the same way, as showed by source [13].

There are a variety of frameworks that have been suggested to allow interoperation between different systems. Usually, they transform the information into more structured data. Source [5] presented some examples in their research: the ATHENA Interoperability Framework (AIF), responsible for capture the research elements and 
solutions to interoperability issues, the European Interoperability Framework (EIF), which describes the different interoperability levels and focus on the interoperability between public entities from various government around Europe, and the INTEROP Network of Excellence (INTEROP NoE).

\section{Preliminary method to support interoperable information exchange in the business process}

The case study is a process in a Brazilian multinational company, more precisely in the logistic system. In that process is done the transport schedule of production commodities. It is necessary to execute two planning: (i) the material collection in suppliers; and (ii) the delivery in a consolidation centre; the transportation from it to eight company's plants around the country and neighbour countries. In that is used data from SAP and suppliers' documents. The current process must be made once a week. The logistic team does some procedures manually, which costs approximately ten hours. Besides that, plenty of mistakes occur accidentally, causing additional costs to the company and rework hours. The enterprise is studying to digitalize the entire process to reduce extra costs and repetitive works.

After reviewing the related works, a solution is proposed for the business process's digital transformation. Its four stages are shown in Figure 3.

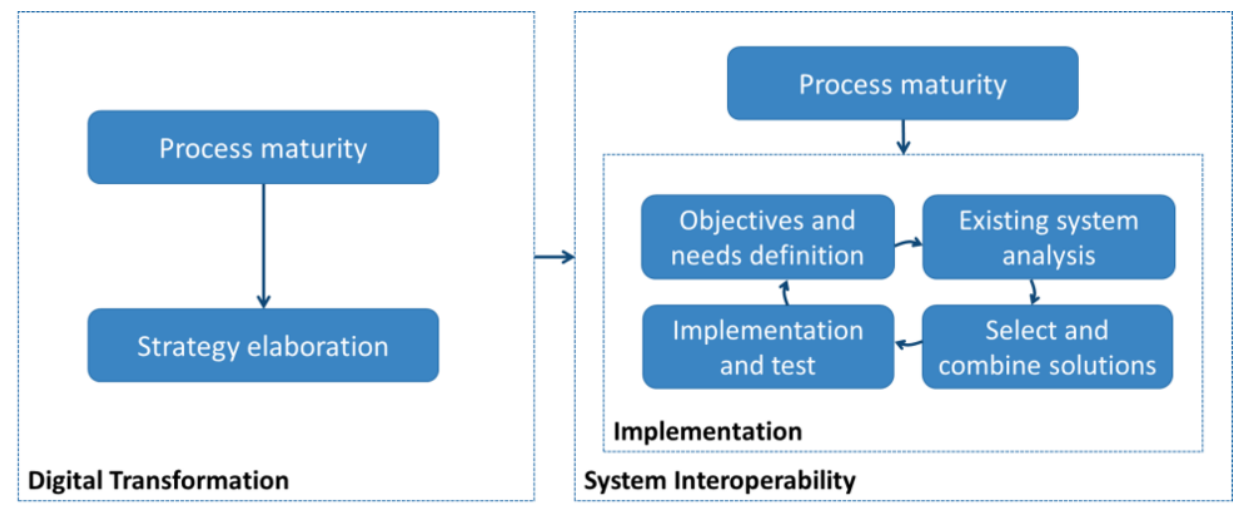

Figure 3. Stages of Business Process's Digital Transformation.

As the first step, it is necessary to measure the digital transformation maturity, in other words, verifying the process transformation stage. It allows us to know how the enterprise approaches its transformation and maps how it can or should be after that. Besides, it is possible to realize what kind of strategy would be more accurate for the case. Two different models can be used, proposed by sources [14] [15].

In the first one, the authors created a list with twenty-eight statements, where each interviewee needs to respond how much does he/she agrees with it, on a scale of zero to three (completely disagree, somewhat disagree, somewhat agree, and completely agree). The questionary is divided into four dimensions: (i) Culture: A company's approach to digitally driven innovation, and how it empowers employees with digital technology; (ii) Technology: A company's use and adoption of emerging technology; (iii) Organization: How aligned a company is to support digital strategy, governance, and execution; and 
(iv) Insights: How well a company uses customer and business data to measure success and inform strategy. The potential score range is $0-84$, and there are four possible maturity stages, presented in Figure 4.

\begin{tabular}{|c|c|c|c|c|}
\hline High & $\begin{array}{l}\text { Maturity } \\
\text { segment }\end{array}$ & $\begin{array}{c}\text { Characteristic } \\
\text { behavior }\end{array}$ & Strategy & Score range \\
\hline \multirow{3}{*}{$\begin{array}{l}\text { Level of } \\
\text { maturity }\end{array}$} & Differentiators & $\begin{array}{l}\text { Leveraging data to } \\
\text { drive customer } \\
\text { obsession. }\end{array}$ & $\begin{array}{l}\text { Blend the digital and } \\
\text { physical words. }\end{array}$ & $72-84$ \\
\hline & Collaborators & $\begin{array}{l}\text { Breaking down } \\
\text { traditional silos. }\end{array}$ & $\begin{array}{l}\text { Use digital to create } \\
\text { competitive advantage. }\end{array}$ & $53-71$ \\
\hline & Adopters & $\begin{array}{l}\text { Investing in skills and } \\
\text { infrastructure. }\end{array}$ & $\begin{array}{l}\text { Prioritize customer over } \\
\text { relationships over } \\
\text { production. }\end{array}$ & $34-52$ \\
\hline Low & Skeptics & $\begin{array}{l}\text { Just beginning the } \\
\text { digital Journey. }\end{array}$ & Prompt a willing attitude. & $0-33$ \\
\hline
\end{tabular}

Figure 4. Distribution into Four Maturity Segments.

In the second model, the author identified six stages of digital maturity, represented in Figure 5, each one representing the company's key moments and milestones through the digital transformation, offering visibility and guidance to the leaders and participants.

For that model, interviewed should identify which level is more proximal to their enterprise reality. It is permitted to select one adjacent stage if there are elements located in both, for example, in a stage transition.

The second stage, where is defined as the transformation strategy, is also described in Figure 4 and Figure 5. For the implementation stage, to measure the interoperability maturity, some models fit with the requirements, such as the Interoperability Measurement Approach (IMA), applied by source [16], and the one presented by source [17] called the Maturity Model for Enterprise Interoperability (MMEI). In this article, the MMEI approach will be explored. It deals with all key interoperability aspects and covers the main concepts of existing interoperability maturity models. MMEI is a long and iterative process, with interoperability potentially view and with a posteriori approach, which means that the interoperation already exists, and the analysis is over the existing interoperability situation. This model allows us to understand the system probability to support efficient interoperations and its weakness.

There are four levels, or stages, of interoperability:

- Level 0 - Unprepared: There is no capability for interoperation

- Level 1 - Defined: Capable of modelling and describing to prepare interoperability

- Level 2 - Aligned: Capable of making changes to align with common formats and standards

- Level 3 - Organized: Capable of metamodeling to interoperate with multiple heterogeneous partners

- Level 4 - Adapted: Capable of dynamically accommodating with any partner

Those levels could be summarized as isolated, connected, integrated, unified, and federated, respectively. 


\begin{tabular}{|c|c|c|c|}
\hline \multirow{3}{*}{ High } & $\begin{array}{c}\text { Maturity } \\
\text { level }\end{array}$ & Characteristic behavior & Strategy \\
\hline & $\begin{array}{l}\text { Innovate or } \\
\text { die }\end{array}$ & $\begin{array}{l}\text { New models, roles, and investments } \\
\text { to accelerate the transformation and } \\
\text { identify new opportunities. }\end{array}$ & $\begin{array}{l}\text { Do not lose momentum. Keep moving } \\
\text { forward, and continuously seek new } \\
\text { opportunities to grow. }\end{array}$ \\
\hline & $\begin{array}{l}\text { Transformed } \\
\text { and } \\
\text { transforming }\end{array}$ & $\begin{array}{l}\text { Leadership transcends this } \\
\text { movement into a new plan around } \\
\text { culture, purpose, and the future } \\
\text { establishment. }\end{array}$ & $\begin{array}{l}\text { All key functions and stakeholders must } \\
\text { be ensured, serving as a rapid decision } \\
\text { team, maintain a cadence for working. }\end{array}$ \\
\hline \multirow{3}{*}{$\begin{array}{l}\text { Level of } \\
\text { maturity }\end{array}$} & Adapt or die & $\begin{array}{l}\text { There are coordinated and } \\
\text { automated efforts between paid, } \\
\text { owned, and earned media. }\end{array}$ & $\begin{array}{l}\text { Assigns a digital transformation leader, } \\
\text { that needs to postpone misaligned } \\
\text { initiatives, removing roadblocks, and } \\
\text { report progress. }\end{array}$ \\
\hline & $\begin{array}{l}\text { Systemize } \\
\text { and } \\
\text { strategize }\end{array}$ & $\begin{array}{l}\text { The organization is getting smarter, } \\
\text { with its change agents seeing the } \\
\text { bigger picture and working formally } \\
\text { toward it. }\end{array}$ & $\begin{array}{l}\text { Places all initiatives according to } \\
\text { priority, identifying parties and } \\
\text { resources needed, also assigning } \\
\text { responsibilities. }\end{array}$ \\
\hline & $\begin{array}{l}\text { Test and } \\
\text { learn }\end{array}$ & $\begin{array}{l}\text { Groups essentially still work in silos } \\
\text { but become increasingly efficient at } \\
\text { experimentation and tracking results. }\end{array}$ & $\begin{array}{l}\text { Develops a list of areas (and its current } \\
\text { state in digital transformation) that } \\
\text { require attention to move to the } \\
\text { following phase. }\end{array}$ \\
\hline Low & $\begin{array}{c}\text { Business as } \\
\text { usual }\end{array}$ & $\begin{array}{l}\text { Just ignoring digital transformation } \\
\text { opportunities, having a risk-averse } \\
\text { culture, and a lack of digital } \\
\text { understanding and infrastructure. }\end{array}$ & $\begin{array}{l}\text { Benchmarks company's place and } \\
\text { documents the attributes accomplished } \\
\text { projects, or that are currently } \\
\text { underway. }\end{array}$ \\
\hline
\end{tabular}

Figure 5. Distribution into Six Stages of Digital Maturity.

Table 1 is presented the focuses and concerns at each maturity level and for each interoperability barrier category.

Table 1. Focuses and concerns of MMEI for each interoperability barrier.

\begin{tabular}{cccc}
\hline $\begin{array}{c}\text { Maturity Levels / } \\
\text { Barriers }\end{array}$ & Conceptual & Technological & Organizational \\
\hline Level 4 - Adapted & Accommodated & Reconfigurable & Agile \\
Level 3 - Organized & Mapped & Open architecture & Trained \\
Level 2 - Aligned & Adhered & Arranged & Flexible \\
Level 1 - Defined & Modelled & Connectable & Specified \\
Level 0 - Unprepared & Incomplete & Inaccessible & Inexplicit \\
\hline
\end{tabular}

The final score of each maturity level is the metric " $M k$ ", calculated from the scores Sij assigned by the evaluators for each interoperability concern " $i$ " and interoperability barrier " $j$ ". It needs to be evaluated using a linear percentage scale, from 0 to $100 \%$. For a maturity level " $k$ ", the following scale can be used: (i) $0<S_{i j} \leq 15$ : not achieved; (ii) $16<S_{i j} \leq 50$ : partially achieved; (iii) $51<S_{i j} \leq 80$ : achieved; (iv) $81<S_{i j} \leq 100$ : fully achieved.

$\mathrm{M}_{\mathrm{k}}$ then is calculated by Equation (1).

$$
M_{k}=\frac{1}{n_{i} \cdot n} \sum_{i, j=1}^{n, n_{i}} s_{i j}
$$


where, " $n_{i}$ " the number of interoperability barriers to evaluate; $n$ the number of interoperability concerns, " $S_{i j}$ " the scale associated with the interoperability concern $\mathrm{j}$ at the interoperability level " $i$ "

This stage is crucial since interoperability is considered one of the most challenging steps to implement collaborative activities and increase collaborative network performance [16].

For the last part, the implementation itself, the authors based on the approach [18], which presented a generical methodology of interoperation implementation, focusing on reducing the time needed to develop interoperability and avoid execution of non-adapted solutions.

The structured approach, where there are four main steps and activities, needs to be followed sequentially, performing several iterations between them.

Step 1. Definition of objectives and needs. To define the performance of interoperability that is aimed, by the levels of maturity.

Step 2. Analysis of existing system. To identify actors, applications, and systems that are involved, as well as problems involving interoperability.

Step 3. Select and combine solutions. To search and select interoperability solutions that take the company's objectives and constraints.

Step 4. Implementation and test. To implement, test, and evaluate the solution encountered to remove the barriers.

The authors also used an enterprise interoperability framework to identify a solution and possible adaptations, the ATHENA Interoperability Framework (AIF). Moreover, the tool supports architectures and platforms, which provide implementation frameworks, and ontology to identify interoperability semantics in the enterprise [19].

After the implementation, a new measurement needs to be executed to verify if the barriers were effectively removed. If not, another iteration is required to adapt the solution or to choose another one. The loop continues until all obstacles are completely removed.

\section{Conclusion and Future Work}

This research presents a preliminary step towards an interoperable system application for enterprises or processes situated in the firsts stages of digital transformation. There is a methodology encompassing the first analysis and strategy selection and the final implementation and system validation. It is crucial since most parts of Brazilian enterprises are in the firsts phases of DX and are starting to digitalize their process and business, implementing interoperability to their heterogeneous systems.

Indeed, this paper provides a methodology that would guide researchers and enterprises through the process of interoperable system implementation, which is significant since most companies are trying to implement it for the first time. This analysis is a necessary activity before starting the digital transformation, principally to select a better implementation strategy.

For future work is planned to apply the methodology proposed for the case previously explained. If necessary, the stages can be reworked to make the method more reliable and with more chances of success. Moreover, it will describe the pros and cons of each step and how they perform in the applied case. Finally, it will present the result of the application in the digital transformation of business. With success, a well-defined methodology can be produced and replied to other processes and even companies. 


\section{References}

[1] E. Henriette, M. Feki and I. Boughzala, Digital transformation challenges. Textile Network, 2016, (5-6), pp. $40-1$.

[2] C. Ebert, C.H.C. Duarte Digital Transformation. IEEE Software, 2018;35, pp. 16-21.

[3] D. Beverungen, J.C.A.M. Buijs, J. Becker, C. di Ciccio, W.M.P. van der Aalst, C. Bartelheimer, et al. Seven Paradoxes of Business Process Management in a Hyper-Connected World. Business and Information Systems Engineering, 2021;63:145-56.

[4] G.C. Kane, D. Palmer, A. Philips Nguyen, D. Kiron, N. Buckley, Strategy, Not Technology, Drives Digital Transformation. MIT Sloan Management Review \& Deloitte, 2015;57181:27.

[5] G. da Silva Serapião Leal, W. Guédria, Panetto H. Interoperability assessment: A systematic literature review. Computers in Industry, 2019;106:111-32.

[6] G. Vial, Understanding digital transformation: A review and a research agenda. The Journal of Strategic Information Systems, 2019, Vol. 28, pp. 118-44.

[7] M.P. Gallaher, A.C. O’Connor, J.L. Dettbarn Jr., L.T. Gilday, Cost Analysis of Inadequate Interoperability in the U.S. Capital Facilities Industry, NIST, CGR 04-867, 2004.

[8] M. Gebhart, P. Giessler, S. Abeck, Challenges of the Digital Transformation in Software Engineering. The Eleventh International Conference on Software Engineering Advances Challenges, 2016, pp. 136-41.

[9] E. Stolterman, A.K. Fors, Information Technology and the Good Life, Information Systems Research: Relevant Theory and Informed Practice. Information Systems Research IFIP International Federation for Information Processing, 2004, pp. 687-92.

[10] M. Fischer, F. Imgrund, C. Janiesch, A. Winkelmann, Strategy archetypes for digital transformation: Defining meta objectives using business process management. Information and Management, 2020, Vol. 57, 103262.

[11] D. Jacobson, G. Brail, D. Woods, APIs: A Strategy Guide. O’Reilly Media, Boston, 2012.

[12] T. Bittner, M. Donnelly, S. Winter, Ontology and Semantic Interoperability. Large-scale 3D Data Integration, CRC Press, Hoboken, 2005, p. 139-61.

[13] C. Steinmetz, G. Schroeder, A. dos Santos Roque, C.E. Pereira, C. Wagner, P. Saalmann, et al. Ontologydriven IoT code generation for FIWARE. 2017 IEEE 15th International Conference on Industrial Informatics (INDIN), IEEE; 2017, p. 38-43.

[14] S. VanBoskirk MG and M. Gill, The Digital Maturity Model 4.0, Forrester, 2016.

[15] B. Solis, The Six Stages of Digital Transformation Maturity. Altimeter Group, 2015.

[16] A. Koulou, M. Zemzami, N. el Hami, A. Elmir, N. Hmina, Optimization in collaborative information systems for an enhanced interoperability network. International Journal for Simulation and Multidisciplinary Design Optimization, 2020, Vol. 11, 2.

[17] W. Guédria, D. Chen, Y. Naudet, A Maturity Model for Enterprise Interoperability. Lecture Notes in Computer, Science, Vol. 5872, 2009, p. 216-25.

[18] R. Wallis et al., Intelligent utilization of digital manufacturing data in modern product emergence processes, Advances in Transdisciplinary Engineering, Vol. 1, 2014, pp. 261-270.

[19] A.-J. Berre, B. Elvesæter, N. Figay, C. Guglielmina, S.G. Johnsen, D. Karlsen, et al. The ATHENA Interoperability Framework. Enterprise Interoperability II, Springer, London; 2007, p. 569-80. 